\title{
Drug company links test journal's policy
}

Washington. Readers of the New England Journal of Medicine (NEJM) are to be told that a signed leading article in the 29 August issue, favourable to a new anti-obesity drug, was written by two doctors who have acted as paid consultants to the companies marketing the drug.

Marcia Angell, executive editor of the journal, says the editors were not aware at the time that one of the article's authors was linked to Interneuron Pharmaceutical Inc., the company which makes the drug dexfenfluramine, marketed as Redux.

Similarly, she adds, the journal did not know that the second author consults for American Home Products Corporation, which, with Interneuron, markets Redux in the United States, and Servier, the French company that markets it in Europe.

News of the leading article, which was leaked ahead of publication, boosted Interneuron's share price by 13 per cent, to $\$ 33.90$. The value of shares in American Home Products rose $\$ 1.50$ to $\$ 61.12$.

"There was in fact a conflict of interest [in] violation of our policy," says Angell. "We are going to alert our readers as soon as we can." She says the issue will be discussed with the editor-in-chief, Jerome Kassirer, on his return from vacation this week, and the journal will then publish a notification of the conflict of interest.

The case, which has received wide coverage in the US media, has reopened a debate about the NEJM's strict policy prohibiting since 1990 leading articles by authors who have "ongoing financial associations" with companies that make products discussed in them. Its policy defines "associations" to include "equity interest, regular consultancies, or major research support."

Competitor journals believe the policy, while based on a desirable principle, is undesirable in practice. George Lundberg, for example, editor of the Journal of the American Medical Association (JAMA), calls it "unreasonable" because the pool of qualified experts on a topic is often small. Instead of disqualifying authors because of their ties with companies, JAMA merely requires authors of leading articles to disclose such ties. "No other journal in the world" applies the NEJM standard, he says.

Uwe Reinhardt, a professor of health economics at Princeton University who formerly served on the board of NEJM, agrees. Reinhardt, who now sits on JAMA's board, says that, in a world of limited numbers of special experts, "when you're too purist you pay a price".

But Angell disagrees, citing the current article as a case in point. Knowledge that the authors were tied to the manufacturers of the drug being studied will affect a reader's interpretation of the content, she says, and inevitably raises the question: are they biased? "The New England Journal of Medicine's point of

\section{'Superman' argues for more NIH money}

\begin{abstract}
Washington. An emotional speech last week on biomedical research funding to the Democratic National Convention by Christopher Reeve, the 43-year-old actor who once played Superman
\end{abstract} but who was paralysed from the neck down in a riding accident in 1995, has not gone without response.

Reeve told the delegates in Chicago - as well as a vast national television audience - that he wanted to "challenge" President Bill Clinton. "Our scientists can do more. We've got to give them the chance. And that means more funding for research."

He then cited spinal cord injury as an example of underfunding, arguing that the government spends $\$ 8.7$ billion a year caring for victims of such injuries, but only $\$ 40$ million on spinal cord injury research. "We've got to be smarter and do better," he concluded.

The next day, Harold Varmus, the director of the National Institutes of
Health (NIH), issued a press release which said that just as spinal cord injury research helps to cure other disorders, so research on diseases such as Parkin-

\& son's “is contributing to our understanding of spinal cord injury".

IMAGE
UNAVAILABLE
FOR
COPYRIGHT
REASONS

Progress in fighting diseases results from the US government's commitment to research "based on scientific excellence rather than on presumed relevance to certain disorders", said Varmus in the statement.

Henry Bonilla, a Republican congressman from Texas, also took issue with Reeve, claiming that Clinton had sought to reduce the NIH's budget in his first year of office, and emphasizing Republican support for the agency. "Let's set the record straight," said Bonilla. "Ever since then we have had to fight him every year to get [the $\mathrm{NIH}$ ] the money they need to keep us head and shoulders above any other country." $\quad$ M. W. view is that no-one should have to wonder."

Nevertheless, Angell says the current situation arose partly out of a "genuine misunderstanding" with the authors, who say they did not consider their arrangements with the drug companies to be regular. Confusion also arose during a telephone conversation in which an NEJM deputy editor is said to have understood from the lead author that both had been consulting for the Food and Drug Administration (FDA), instead of for the companies. Angell says she accepts that the authors did not deliberately intend to deceive the journal or its readers.

The two authors argued that the risk of taking Redux, an appetite-suppressant associated with a rare but fatal lung disorder, "appears to be outweighed by the benefits when the drug is used appropriately". They estimated that 280 lives would be saved by the anti-obesity drug for every 14 people who died from the lung condition, primary pulmonary hypertension.

The authors, JoAnn E. Manson, an associate professor at the Harvard Medical School, and Gerald A. Faich, an adjunct professor at the University of Pennsylvania Medical School, were asked by the NEJM to write the article.

Both say the NEJM policy is ambiguous, as they did not believe that their contact with companies linked to Redux amounted to "regular consultancies". Manson consulted for Interneuron in the autumn of 1995, while the FDA was reviewing the drug. She testified to an FDA panel twice on behalf of Interneuron.

Faich, who began consulting for Servier in 1994, said his "ad hoc" work has consumed less than five per cent of his time in 1996 . He testified twice to the FDA on Servier's behalf in the fall of 1995. Faich says he also did 14 hours of work for American Home Products in April, May and June 1996, "on regulatory matters, not on commercial matters". He also worked for the company last month, after the article had been submitted.

"The type of consulting I was doing was by no means 'regular' and it was not 'ongoing," says Manson. "So there was much room for interpretation of NEJM's policy." She proposed that a disclosure accompany the article, saying that neither author has any financial interest or equity in any drug company producing anti-obesity agents.

Angell says she did not understand from the proposal that the authors had consulted for the drug companies. The suggested wording, while perhaps technically correct, "omit[s] mention of the companies... and consultancy".

There was "no motivation to deceive anyone," says Faich. But "I now of course recognize and deeply regret any problems I've caused the New England Journal or its readership." 